\title{
Analysis of metal element contents in soil sample of different altitude from lead-zinc tailing mine mount in Longnan City, Gansu Province
}

\author{
Zhuoxin Yin ${ }^{1}$, Yao Zheng ${ }^{1}$, Zhengzhou Wang ${ }^{1}$, Bin Yue ${ }^{1}$ and Guohua Chang ${ }^{1, *}$ \\ ${ }^{1}$ College of Geography and Environmental Engineering, Lanzhou City University, Jiefang Road 11 Anning District Lanzhou City, China
}

\begin{abstract}
Contents of metal elements in soil covered lead-zinc tailing mine should be determined after longterm exposured with tailing ores, results should be compared with the requirements of metal contents in National Standards in order to measure the the application level of land. The investigation of this paper chose the representative soil samples of different altitude from multiple soil samples collected from the soil covered lead-zinc tailings mine mount in Cheng County, Longnan City, Gansu Province in China. XRF analysis was used to determine the kind and content of metal elements of the soil sample. The data were compared to make sure the changes of metal elements contents of soil samples with the altitude. The result found that the maximum content of Fe in each sample, and the content of Fe is quite different of the content of other metal elements in samples, while the samples had relatively low contents of $\mathrm{Pb}$ and $\mathrm{Zn}$. Content of $\mathrm{Cu}$ in soil samples is lower than the Risk Screening Value of Soil Pollution in Construction Land, while contents of $\mathrm{Pb}$ and $\mathrm{Cr}$ were higher than that in Risk Screening Value of Soil Pollution in Construction Land.
\end{abstract}

\section{Introduction}

Longnan City was located in southeastern part of Gansu Province in China, and its geographical latitude and longitude coordinates were between N 32 $38^{\prime} \sim 34^{\circ} 31^{\prime}$ and $\mathrm{E} 104^{\circ} 1^{\prime} \sim 106^{\circ} 35^{\prime}$. Longnan City was the exclusive Changjiang River basin region in Gansu Province, the only subtropical humid climate zone [1]. Local area of Longnan City had the East Asian monsoon climate with significant vertical zoning. The precipitation was closely related to local topography, the terrain change and hydrothermal distribution had great influence on production and living. It was rich in water, biological and mineral resources [2]. The altitude of Chengxian County in Longnan City was between $750 \mathrm{~m}$ and $2377 \mathrm{~m}$ [3-5]. As the miscellaneous metal elements in lead-zinc tailings mine could migrate to natural surrounding environment in long-term open storage of tailings, contents of metal elements in soil covered lead-zinc tailings mine should be tested. Soil samples investigated in this paper were collected from the soil covered lead-zinc tailings mine mount of altitude from the top to bottom of $1074-1248$ $\mathrm{m}$ in Anfanggou Ditch of Chengxian County in Longnan City, Gansu Province, China. Contents of heavy metal in soil were not only affected by the eluviation and efflorescence during soil-forming process, but also influenced by plant absorption, enrichment, naturalization and other factors. However, various human activities impacted metal contents in soil of different functional areas as well.
Infiltration and diffusion of metal elements in ores as the result of the stacking of lead-zinc tailing mine. And also the metal elements in tailing ore could be dissolved by the acid in acid mine drainage water, and entered the water environment as the mine drainage and rainfall, or directly entered the soil, which could cause heavy-metal pollution of soil directly or indirectly. Soil heavy metal pollution may cause the phenomena of soil quality degradation of existing and potential soil source, deterioration of ecology and environment.

Scientific analysis of metal elements contents measured by XRF in collected soil sample to get clear about the spatial distribution pattern and pollution intensity of metal contents in soil samples from soil covered lead-zinc tailing mine, it was important to discover the main reason of heavy-metal contamination, to determine the location of pollution sources and pollution prevention and control [6].

$\mathrm{X}$-ray fluorescence analysis method was used in the research process to determine the kind and content of metal elements of the soil sample with particle size of 2 $\mathrm{mm}$ after treatment and screening, the data obtained wer analyzed and discussed. The determined original data were analyzed, and the contents of metal elements in different soil samples were classified by element type, and the average content of each metal element in all collected soil sample were calculated.

\footnotetext{
* Corresponding author: cgh@1zcu.edu.cn.
} 


\section{Methods and Materials}

\subsection{Method for collecting soil samples}

The lead-zinc tailings mine area in Chengxian County, Longnan City, where the soil samples were collected was built along the mountside, the spatial construction of tailings mine was laminated like terrace, with stripstepped cross section. We collected soil samples of different altitude from the foot to the top of the mount in different heights of the lead-zinc tailing mine in the strip terrace plane obliquely cut from the side of the tailing mine mount. When the soil samples were collected, the weeds and gravel and other debris on the soil surface were pushed aside, the undersoil was digged with shovels and the mixed stones were picked out, the depth of digging was between $1 \mathrm{~cm}$ to $10 \mathrm{~cm}$. Acquired soil samples were put into the sealed plastic sample bags, marking the acquisition time and location, and recording the geographical position of sampling collecting sites with hand-held GPS. Then the according sampling collecting time was compared with GPS records to determine the altitude and coordinates of sampling collecting sites.

\subsection{Soil sample treatment and determination method of metal elements contents}

Table1. Coordinates of soil sampling sites.

\begin{tabular}{|c|c|c|c|}
\hline $\begin{array}{c}\text { Sample } \\
\text { No. }\end{array}$ & Altitude(m) & Latitude(N) & Longitude(E) \\
\hline 1 & 1075 & $33^{\circ} 50^{\prime} 22.59^{\prime \prime}$ & $105^{\circ} 43^{\prime} 53.82^{\prime \prime}$ \\
\hline 2 & 1153 & $33^{\circ} 50^{\prime} 26.70^{\prime \prime}$ & $105^{\circ} 44^{\prime} 00.66^{\prime \prime}$ \\
\hline 3 & \multirow{2}{*}{1199} & \multirow{2}{*}{$33^{\circ} 50^{\prime} 29.90^{\prime \prime}$} & \multirow{2}{*}{$105^{\circ} 44^{\prime} 04.33^{\prime \prime}$} \\
\hline 4 & & & \\
\hline 5 & \multirow{2}{*}{1246} & \multirow{2}{*}{$33^{\circ} 50^{\prime} 35.92^{\prime \prime}$} & \multirow{2}{*}{$105^{\circ} 44^{\prime} 04.06^{\prime \prime}$} \\
\hline 6 & & & \\
\hline 7 & \multirow{2}{*}{1248} & \multirow{2}{*}{$33^{\circ} 50^{\prime} 34.55^{\prime \prime}$} & \multirow{2}{*}{$105^{\circ} 44^{\prime} 05.12^{\prime \prime}$} \\
\hline 8 & & & \\
\hline
\end{tabular}

Collected soil samples were unified screening after natural drying, and the hand-held X-ray fluorescence (XRF) heavy metal analyzer(S1-TITAN, BRUKE) was used to determine the contents of metal elements in soil samples, the data used in this paper were measured results of soil samples through $2 \mathrm{~mm}$ sieve. Eight soil samples selected for the paper were collected from different altitudes, and were numbered in accordance with low to high altitude. The coordinate positions of sites for soil samples are listed in Table 1 by number. Some soil samples were collected in the different sites of the same coordinate.
Table2. Contents of metal elements in soil samples.

\begin{tabular}{|c|c|c|c|c|}
\hline \multirow{2}{*}{$\begin{array}{c}\text { Sample } \\
\text { No. }\end{array}$} & \multicolumn{4}{|c|}{ Contents of Metal Elements $\left(\mathrm{mg} \cdot \mathrm{kg}^{-1}\right)$} \\
\hline & $\mathrm{Cr}$ & Mn & $\mathbf{F e}$ & $\mathbf{N i}$ \\
\hline 1 & 27.33 & 426.33 & 20666.67 & 39.67 \\
\hline 2 & - & 419.67 & 25000.00 & 13.67 \\
\hline 3 & 83.67 & 704.33 & 37666.67 & 6.33 \\
\hline 4 & 59.33 & 131.00 & 10679.33 & 41.33 \\
\hline 5 & 79.33 & 353.67 & 25000.00 & 13.00 \\
\hline 6 & 19.67 & 232.33 & 8666.67 & 33.33 \\
\hline 7 & 74.00 & 189.33 & 6450.67 & - - \\
\hline 8 & 93.00 & 246.00 & 10217.67 & 0.00 \\
\hline Average & 62.33 & 337.83 & 18043.46 & 21.05 \\
\hline \multirow{2}{*}{$\begin{array}{c}\text { Sample } \\
\text { No. }\end{array}$} & \multicolumn{4}{|c|}{ Contents of Metal Elements $\left(\mathrm{mg} \cdot \mathrm{kg}^{-1}\right)$} \\
\hline & $\mathbf{C u}$ & Zn & $\mathbf{W}$ & $\mathbf{P b}$ \\
\hline 1 & 48.67 & 295.67 & 7 & 177.33 \\
\hline 2 & 67.33 & 586 & 9.67 & 292 \\
\hline 3 & 48 & 129.67 & - - & 40.33 \\
\hline 4 & 62.67 & 2645 & 15 & 1349 \\
\hline 5 & 38 & 54.67 & 4.33 & - \\
\hline 6 & 39.33 & 55.67 & - - & - \\
\hline 7 & 106 & 828 & 17.33 & 644 \\
\hline 8 & 28 & 53.33 & 10.67 & 16.67 \\
\hline Average & 54.75 & 581.00 & 10.67 & 419.89 \\
\hline
\end{tabular}

\section{Results and Discussion}

\subsection{Comparison of Determination Results of types and contents of Metal Elements in Soil Samples}

Comparison of samples showed the colour of soil samples changed by brown gradually deepened with the 
decreasing altitude, from light-gray of soil sample in mount top to black-brown of soil sample in mount bottom. According to comparation of the XRF determination results of the types and contents of metal element in soil samples, 11 kinds of metal elements were analyzed in 8 soil samples, most of them were heavy-metal elements. In addition to $\mathrm{Pb}$ in the IVA main group and the sixth period of the periodic table, the others were all the transition metal, as the $\mathrm{Cr}, \mathrm{Mn}, \mathrm{Fe}, \mathrm{Ni}, \mathrm{Cu}$ and $\mathrm{Zn}$ in the forth period, the $\mathrm{Ag}, \mathrm{Cd}$ in the fifth period, and $\mathrm{W}, \mathrm{Au}$, and $\mathrm{Hg}$ in the sixth period. While contents of some metal in some soil samples were not determined by XRF detector, only Ag was measured in Sample 7, Hg was measured in Sample 3, $\mathrm{Cd}$ and $\mathrm{Au}$ were measured in Sample 8. However, the other 8 kinds of metal elements were nearly measured in all 8 soil samples. The contents of various metal elements are listed according to the sample number, and the results are shown in Table 2. According to comparation of the XRF determination results of the types and contents of metal element in soil samples, eleven kinds of metal elements were analyzed in eight soil samples. In addition to $\mathrm{Pb}$ in the IVA main group and the sixth period of the periodic table, the others were all the transition metal, as the $\mathrm{Cr}, \mathrm{Mn}, \mathrm{Fe}, \mathrm{Ni}, \mathrm{Cu}$ and $\mathrm{Zn}$ in the forth period, the $\mathrm{Ag}$, $\mathrm{Cd}$ in the fifth period, and $\mathrm{W}, \mathrm{Au}$, and $\mathrm{Hg}$ in the sixth period. While contents of some metal in some soil samples were not determined by XRF detector, only Ag (8.33 $\left.\mathrm{mg} \cdot \mathrm{kg}^{-1}\right)$ was measured in Sample $7, \mathrm{Hg}(9.67$ $\left.\mathrm{mg} \cdot \mathrm{kg}^{-1}\right)$ was measured in Sample 3, Cd (3.33 mg $\left.\mathrm{kg}^{-1}\right)$ and $\mathrm{Au}\left(45.67 \mathrm{mg} \cdot \mathrm{kg}^{-1}\right)$ were measured in Sample 8 . However, the other 8 kinds of metal elements were nearly measured in all 8 soil samples. The contents of various metal elements are listed according to the sample number, and the results are shown in Table 2.

To compare the contents of metal elements in soil samples covering lead-zinc tailings mine, according to the data in the Table 2, in all 8 soil samples, the content of Fe $\left(37666.67 \mathrm{mg} \cdot \mathrm{kg}^{-1}\right)$ was the highest, next was zinc $\left(2645.00 \quad \mathrm{mg} \cdot \mathrm{kg}^{-1}\right)$, lead $\left(1349 \mathrm{mg} \cdot \mathrm{kg}^{-1}\right)$, maganese $\left(704.33 \mathrm{mg} \cdot \mathrm{kg}^{-1}\right)$, copper $\left(106.00 \mathrm{mg} \cdot \mathrm{kg}^{-1}\right)$, chromium (83.68 $\left.\mathrm{mg} \cdot \mathrm{kg}^{-1}\right)$, nickel(41.33 $\mathrm{mg} \cdot \mathrm{kg}^{-1}$ ) and tungsten $\left(17.33 \mathrm{mg} \cdot \mathrm{kg}^{-1}\right)$. Although the soil samples were collected from lead-zinc tailing mines, the content of $\mathrm{Zn}$ and $\mathrm{Pb}$ was lower than that of Fe. While the soil samples with the highest $\mathrm{Zn}$ and $\mathrm{Pb}$ contents were not Samples 1 and 8 collected from the top and foot of the tailings mount, but the Sample 4 from the sampling site with altitude (1199 $\mathrm{m}$ ) at the middle of mountainside, and soil sample with the highest content of Fe, $\mathrm{Mn}$ and $\mathrm{Cr}$ is Sample 3 in the middle elevation of the tailiing mount. The results showed that contents of heavy metal measured in soil covered lead-zinc tailing mine had large amplitude of variation and heterogeneous distribution.
Table3. National Standard Requirment for contents of metal elements.

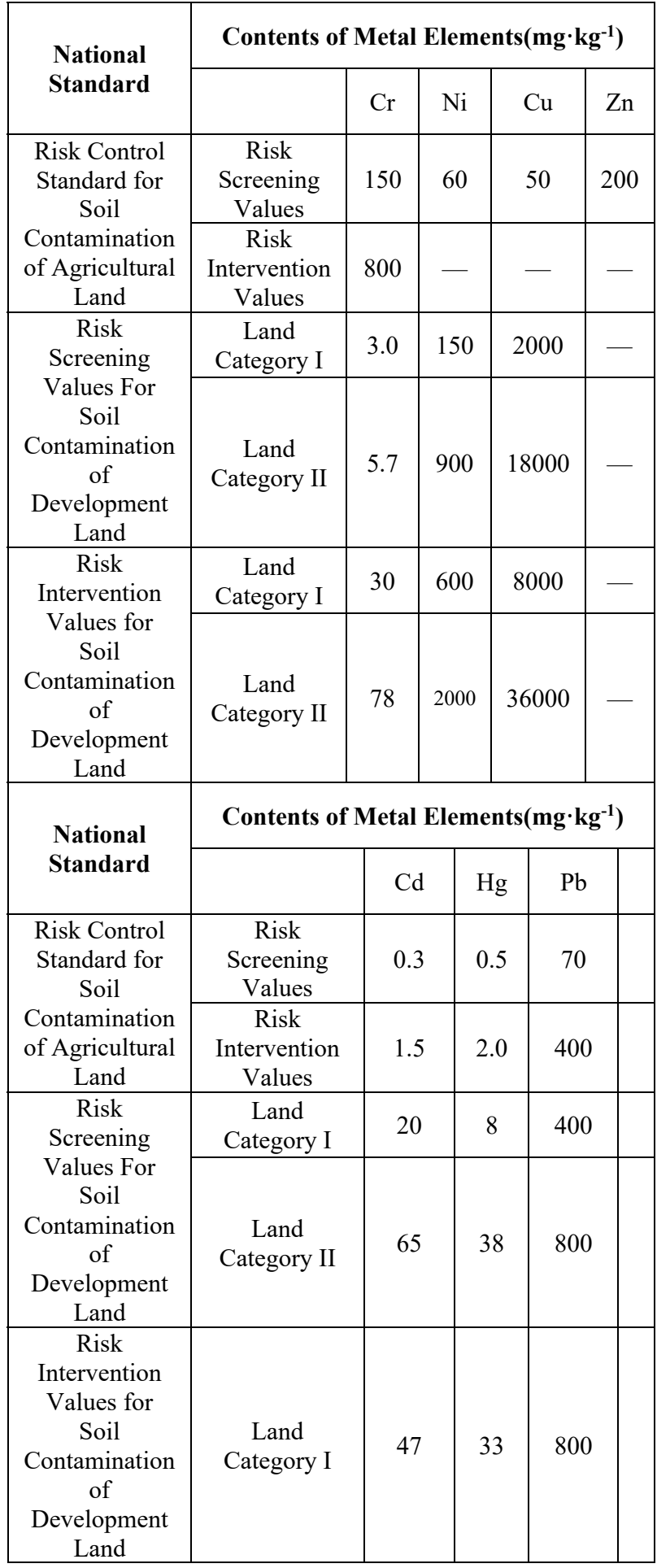

The reason for the highest contents of metal elements were found in Samples 3 and 4 collected from tailings hillside probably was leaching effect made the migration of transition metal Elements from the high altitude soil to low altitude soil. And because of the change of $\mathrm{pH}$, the migration rates of metal ions with different atomic numbers and atomic weights in soil are different, thus lead to differences in the content of metal elements in soil samples. However, the contents of $\mathrm{Pb}$ and $\mathrm{Zn}$ in lead-zinc tailings mine are lower than that in raw ore, so although 
Samples were collected from soil covered lead-zinc tailing mine, the contents of $\mathrm{Pb}$ and $\mathrm{Zn}$ is lower than that of Fe. Since Fe has a high content in soil samples as an associated element of a variety of transition metal ores [4, 5], maybe because iron has different oxidation state and was easy to form various compounds.

\subsection{Comparation of metal elements contents in soil samples with that in National Standard}

Land could be divided into agricultural land and development land by the usage category. Different types of land have different standards requirements for metal content. As the contents of metal elements in National Standard had some differences under different conditions, the mimimus value of risk screening values and risk intervention values for soil contamination of agricultural land in Risk Control Standard for Soil Contamination of Agricultural Land were selected in Table 3. Comparing the measured contents of metal elements in soil samples with the screening value and control value of relevant heavy metal contents standards in National Standards [6, 7] in Table 3, the comparison results were as follows. The city development land could be classified into Land Category I and II, while Land Category I was mainly Residential land in urban development land, Land Category II was mainly industrial land in urban development land.

In all soil samples, contents of $\mathrm{Cr}$ were all lower than that in risk screening values and risk intervention values for soil contamination of agricultural land, but higher than that in risk screening values for soil contamination of development land; while the maximum $\mathrm{Cr}$ content was a little higher than the risk intervention values for soil contamination of development land (Land Category II). There were no requirements for contents of $\mathrm{Mn}$ and $\mathrm{Fe}$ in soil National Standards. Content of $\mathrm{Ni}$ in soil samples were all under that of land in National Standard.

Contents of $\mathrm{Cu}$ in some soil samples were a little higer than that in Risk Screening Values for Soil Contamination of Agricultural Land, but all lower than the Risk control standard for soil contamination of development land [7, 8]. Contents of $\mathrm{Zn}$ in some soil samples were higher than the Risk Control Standard for Soil Contamination of Agricultural Land, while Risk Control Standard for Soil Contamination of Development Land did not require content of $\mathrm{Zn}$. Contents of $\mathrm{Pb}$ in some soil samples were higher than that in Risk Control Standard For Soil Contamination Of Development Land, risk screening values and risk intervention values for soil contamination of development land (Land Category I), but they were all lower than that in Risk Intervention Values For Soil Contamination Of Development Land (Land Category II).

\section{Conclusion}

In Summary, results of analysis of metal element Contents in Soil Sample of different altitude from lead-zinc tailings mine mount in Anfanggou Dintch of Bijiashan Mountion, Longnan City, Gansu Province were listed as follows.
1) The results of the comparison of types and contents of metal elements in soil samples from the soil covering the lead-zinc tailing mine showed that in eight metal elements determined in soil samples, the contents of Fe were highest, while contents of $\mathrm{W}$ were lowest, and contents of $\mathrm{Pb}$ and $\mathrm{Zn}$ were moderate. The maximum contents of metal elements were in soil samples in the middle altitude of tailing mine mount. Eight kinds of metal elements were determined in most soil samples, but $\mathrm{Ag}, \mathrm{Cd}, \mathrm{Au}$ and $\mathrm{Hg}$ were only determined in three soil samples.

2) Comparing the Metal Contents in Soil Samples with that in National Standards, the results showed that the contents of $\mathrm{Cr}, \mathrm{Ni}$ and $\mathrm{Pb}$ were both lower than that in Risk Control Standard for Soil Contamination of Agricultural Land, while the content of $\mathrm{Cr}$ was a little higher than that in risk screening values for soil contamination of development land. Contents of $\mathrm{Cu}$ and copper were a little higher than that in Risk Control Standard for Soil Contamination of Agricultural Land. Contents of $\mathrm{Pb}$ were higher than that in risk intervention values for soil contamination of development land (Land Category I), but lower than that in Land Category II. For the soil samples determined other metal elemts, contents of $\mathrm{Cd}$ and $\mathrm{Hg}$ were higer than that in Risk Control Standard for Soil Contamination of Agricultural Land, while content of $\mathrm{Hg}$ was lower than that in Risk Control Standard for Soil Contamination of Development Land.

\section{Acknowledgement}

This research was funded by the Scientific Research Projects in Colleges and Universities from Gansu (2019B-169) and the Doctoral Research Fund of Lanzhou City University (LZCUBS2019-26).

\section{References}

1. K. Wei. Lanzhou University. (2014)

2. Y. Lu. Gansu Metallurgy. 31, 01 (2009)

3. H. Liu. Gangsu Science and Technology. 31, 17 (2015)

4. D. Peng. Contributions to Geology and Mineral Resources Research. 04 (1998)

5. C. Wang. Gold Science and Technology. 05 (2001)

6. C. A. Cambardella, T. B. Moorman, J. M. Novak, T. B. Parkin, D. L. Karlen, R. F. Turco, A. E. Konopka. Soil Sci. Soc. Am. J. 58 (1994)

7. Ministry of Ecology and Environment, State Administration of Market Supervision and Administration. GB 15618_2018. (2018)

8. Ministry of Ecology and Environment, State Administration of Market Supervision and Administration. GB 36600_2018. (2018) 